Ethiopian Journal of Environmental Studies \& Management 8(5): 570 - 578, 2015.

ISSN:1998-0507

doi: http://dx.doi.org/10.4314/ejesm.v8i5.10

Submitted: March 17, 2015

Accepted: July 15, 2015

\title{
URBAN HOUSING QUALITY AND ITS HEALTH IMPLICATIONS IN NIGERIA: AN EXAMPLE OF LOKOJA, KOGI STATE, NIGERIA
}

*ADETUNJI, M.A. AND ISAH, I.O.

Department of Geography, Faculty of Arts and Social Science, Federal University Lokoja, Kogi

State, Nigeria

\begin{abstract}
Developing countries are faced with qualitative and quantitative housing inadequacies. Living conditions in many urban areas are squalid and pose serious health challenges on the inhabitants. This study examines the housing quality and its health implications in Lokoja metropolis. Both primary and secondary data were employed. A structured questionnaire was designed. An average of forty questionnaires was distributed across each of the three residential areas identified in the city to elicit information about the types of residential units occupied by the residents of the city and the facilities available in their houses such as toilets, electricity, and drainage. Secondary data was obtained from documentary sources. Descriptive and inferential statistics were employed to analyze the data. The findings reveal that more than $60 \%$ of the inhabitants live in indecent houses. The cost of housing is exorbitant to an average household in the city. This may advance the reasons substantial numbers of urban residents live in slum areas which are affordable to them. Further analysis reveals that the quality of housing varies across the residential areas identified in the city. Similarly, environmental health challenges vary across the three residential areas in Lokoja. The study recommends that low cost housing scheme should be established in Lokoja as this may reduce housing problems in the city. Also, this will enable the urban residents to live in a healthy environment and consequently improve the standard of living of urban dwellers in Lokoja.
\end{abstract}

Key Words: Housing, Quality, Poverty, Facilities and Planning

\section{Introduction}

Housing quality refers to structural attributes and facilities provided for the inhabitants of a building to live a decent life. The structural attributes of housing refer to materials used to build houses such as mud, thatch, corrugated iron sheets, wood, while the internal facilities include pipe water, access to toilets and electrical appliances (Bradley and Putnick, 2012). In a research conducted on housing quality in Benin, Nigeria, Moughalu (1991) found that about
$80 \%$ of dwellings in the city met minimum standards for external construction materials but less than half of the buildings met minimum standards for internal facilities. In a similar study carried out in Ondo in south western Nigeria, an approximately $80 \%$ of residents lived in households having three rooms or fewer, nearly $40 \%$ of which were not in good condition (Aribigbola, 2008). Also, another study carried out in Ghana revealed that majority of residents lived in substandard houses, especially those living

*Corresponding author: Adetunji, M.A.

Email: musilimuadetunji@yahoo.com 
in the rural communities (Fiadzo, 2004). Provision of drinkable water is a significant factor in determining good housing quality. In a study of household accessibility to drinkable water in Sub Saharan African countries, the quality of drinking water is a powerful environmental determinant of health. Assurance of drinking-water safety is a foundation for the prevention and control of waterborne diseases. (http://www.who.int/water_sanitation_health /dwq/en/)

The issue of sanitary facilities in developing countries is a serious concern to all and sundry. In a joint press release by Unicef and World Health Organization in 2008, approximately sixty-two per cent of Africans do not have access to an improved sanitation facility which separates human waste from human contact. Approximately 2.6 billion people around the world who live without access to toilet at home are vulnerable to a range of health risks. Also, forty per cent of the world's population lack access to toilets. And studies have shown that improving access to sanitation helps to create a physical environment that enhances safety, dignity and self-esteem. Safety issues are particularly important for women and children, who otherwise risk sexual harassment and assault when defecating at night and in quiet areas (http://www.who.int/mediacentre/news/relea ses/2008/pr08/en/). The main objective of examining housing characteristics is to determine the quality of life of urban residents in any geographical space. The type of house an individual lives in is one of the parameters used to determine the quality of life of the people. (Meng and Hall, 2006; Roberts et al., 2001). Even though more research conducted on housing characteristics focuses on major urban centres in Nigeria particularly Lagos, Ibadan, Kano and Port Harcourt (Aluko,
2011; Gambo et al., 2012; Dankani, 2013). Despite numerous research with laudable recommendations for alleviating housing problems in some of these cities, acute shortage of housing and substandard buildings ravage some these emerging cities in Nigeria. It is against this background that this study is designed to examine housing characteristics in Lokoja, a city located in the north central part of Nigeria where more than ten ethnic groups reside with different cultural backgrounds. The cultural difference in this city may affect patterns and characteristics of house types, which may have implications on the quality of housing occupied by residents of the city.

\section{Study Area}

Lokoja metropolis is the study area and it is located on the confluence of River Niger and River Benue. It is the capital city of Kogi State and can be found between latitude $7^{\circ} 45^{\prime} 27.56^{\prime \prime}-7^{\circ} 51^{\prime} 04.34^{\prime \prime} \mathrm{N}$ and longitude $6^{\circ} 41^{\prime} 55.64^{\prime \prime}-6^{\circ} 45^{\prime} 36.58^{\prime \prime} \mathrm{E}$ of the equator with a total land coverage of about 63.82 sq. km. (Adeoye, 2012). In a study of land use / land cover change in Lokoja, Adeoye (2012) reported that natural environment particularly vegetation, wetland resources, water bodies and mountain terrain were threatened as they were reducing gradually in the area extent over time, while the built up area expand massively. The built up area of Lokoja is located at the eastern part of River Niger, while the Mount Patti is located at the western part of the city (figure 1). These two physical features act as an impediment to the growth and development of the city. Since its creation as the headquarters of Lokoja local Government in 1976 and the state capital of Kogi state in 1991, it has witnessed high rate of urbanization within the last three decades, which is a major characteristic of urban centres in Nigeria (Olawepo, 2009). The upsurge in population growth in the town 
over the years has led to acute shortage of decent accommodation for inhabitants and high inflation rate on available houses in the city. This could largely be responsible for the reason why substantial number of urban residents in Lokoja live in slum areas and uncompleted buildings in an attempt to cut down the exorbitant price of accommodation in the city.

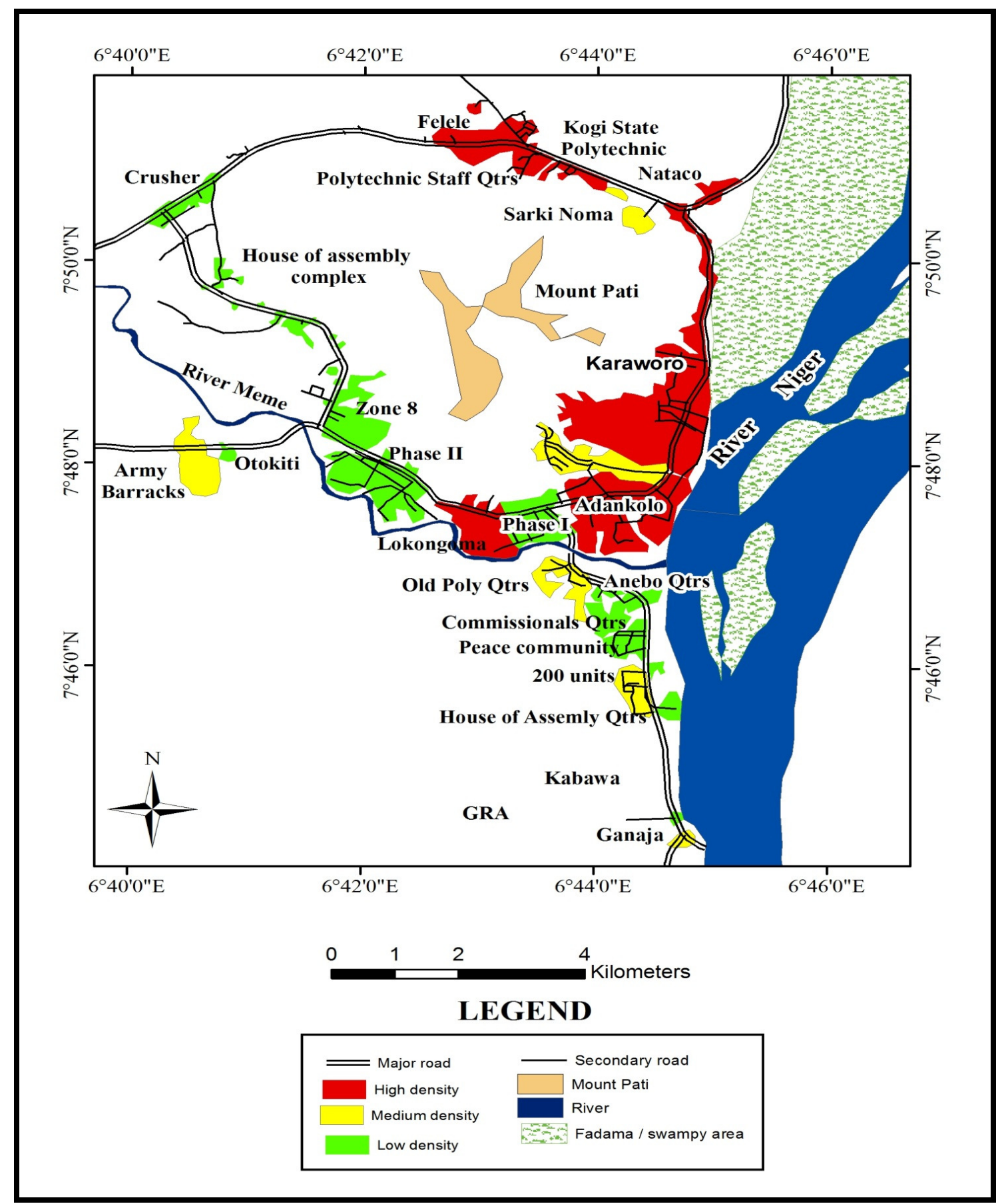

Figure 1: Map of the study Area showing Residential Areas. 


\section{Materials and Methods}

Lokoja Metropolis was classified into three residential areas based on large use characteristics and population concentrations. Both primary and secondary data were employed. A structured questionnaire was designed to elicit information about the types of residential units occupied by the residents of the city and the facilities available in their houses such as toilets, electricity and drainage system. A systematic random sampling technique was employed to administer an average of forty questionnaires to the head of each household along the major roads in each of the residential areas identified in the city. The administration of questionnaire is based on the principle that one in every 20 buildingis selected for questionnaire administration. In each of the sampled buildings, questionnaires were administered to only one head of a household. The secondary data was obtained from documentary sources. Descriptive and inferential statistics were employed to analyze the data.

\section{Result and Discussion}

\section{Housing Characteristics in Lokoja}

The findings reveal that houses in the inner core of Lokoja are built with mud block with little or no ventilation as many of these buildings are clustered together. Even though some of these houses are built more than hundred years ago, they are still occupied by indigenous people without any changes. It is pertinent to note that many of the buildings at the high density areas of the study area particularly at Adankolo, Kabawa Angwan Fulani and Karaworo have no access road. Many of the occupants of buildings in these areas of the city cannot move freely without body contact because many of the developers of the buildings did not comply with the planning regulations. At
Angwan Fulani, more than thirty buildings are clustered together. There is little or no sign of separation among the buildings. This type of residential development is called compound settlement. There is little or no ventilation despite the hot weather condition in the city. Table 1 below reveals that $34.7 \%$ of the households sampled in the city occupy a one- roomed apartment, $24 \%$ of the residents indicated that they occupied one bedroom flat. Another $11.2 \%$ and $10.2 \%$ of the respondents claimed that they occupy two bed-roomed houses and three bedroomed apartments respectively. This implies that more than $60 \%$ of the households interviewed in the city could not afford more than a two-bed roomed apartment. Further analysis indicates that approximately $19.4 \%$ of the inhabitants of Lokoja live in more than a three-bedroomed apartment. The last category of the people live on the outskirts of the city and are economically buoyant to afford to occupy more than a three-bedroom flat despite the high cost of accommodation in the city. The result of this analysis is tangential to the study carried out in south western Nigeria by Aribigbola in 2008 in which he reported that an approximately $80 \%$ of residents lived in houses having three rooms or fewer, nearly $40 \%$ of which were not in good condition.

Table 1: Types of Residential unit Occupied by Households Member

\begin{tabular}{ll}
\hline Types of houses & Percentage \\
\hline One room apartment & 34.7 \\
A bedroom flat & $24.5 \%$ \\
Two bedroom flat & $11.2 \%$ \\
Three bedroom latf & $10.2 \%$ \\
More than three bedroom flat & $19.4 \%$ \\
Total & $100.0 \%$ \\
\hline
\end{tabular}

In spite of the acute shortage of housing accommodation in the city where more than two thirds of the households occupy one bedroom apartment, the average household 
size occupying different types of residential units identified in the city is another important factor which requires more to be desire. Table 2 below shows that $50.1 \%$ of the households interviewed in Lokoja claimed that they have an average of five members in a house. Another $31.6 \%$ of the respondents indicate that they have an average of 6-10 members of their family in one house. Approximately $18.3 \%$ of the households interviewed indicated that they have more than 10 people in their family. The largest proportion (12.2\%) of the households sampled who indicated that they have a household size of more than 10 people reside in high density areas of the city, where the buildings are clustered together with little or no ventilation. Many members of the household interviewed expressed their dissatisfaction about the house they occupy but they claimed that they could not help the situation.

Table 2: Household size in Percentage

\begin{tabular}{lccl}
\hline $\begin{array}{l}\text { Residential } \\
\text { Density }\end{array}$ & $1-5$ & $6-10$ & $\begin{array}{l}\text { More than } \\
10\end{array}$ \\
\hline High Density & 16.3 & 12.2 & 12.2 \\
Medium Density & 19.4 & 13.3 & 5.1 \\
Low Density & 15.3 & 6.1 & 1.0 \\
Total & 50.1 & 31.6 & 18.3 \\
\hline
\end{tabular}

With respect to the structural pattern of buildings in Lokoja, many of the houses occupied by the inhabitants of the city are uncompleted buildings. Some of the buildings are not plastered, with few having sealing or asbestos. Table 3 below shows that $56.6 \%$ of the respondents indicate that their houses were not fenced, while the remaining $43.5 \%$ of the households interviewed claimed their houses were fenced.

Table 3: Residential Buildings with Fence in Percentage

\begin{tabular}{lll}
\hline Residential Density & Yes & No \\
\hline High Density & 17.2 & 23.2 \\
Medium Density & 18.2 & 19.2 \\
Low Density & 8.1 & 14.1 \\
Total & 43.5 & 56.5 \\
\hline
\end{tabular}

\section{Access to Potable water}

Water is essential for sustainable human development. Access to portable water will improve the health status of people in any geographical space. There are different sources of water available for urban residents in Lokoja. For instance, Table 4 indicates that $59.2 \%$ of inhabitants of the city have access to tap water. The majority of these people live in High and Medium density areas of Lokoja. Further analysis shows that $11.2 \%$ of the residents in Lokoja rely on well water for their domestic uses, which might have been contaminated with water borne diseases. Akin to this finding, Lindskog and Lundqvist (1998) affirmed that contaminated drinking water is a major source of cholera and diarrhea in rural area in Malawi. A significant population (27.6\%) of the inhabitants of the city relies on bore holes. The last category of this respondent resides in the low density parts of the study area particularly at ZangoDaji and Felele.

Table 4: Sources of Water in Lokoja

\begin{tabular}{lllll}
\hline Residential Density & Tap Water & Well Water & Stream or River & Bore Hole \\
\hline High Density & 36.7 & 1.0 & 1.0 & 0.0 \\
Medium Density & 19.4 & 10.2 & 1.0 & 8.1 \\
Low Density & 3.1 & 0.0 & 0.0 & 19.5 \\
Total & 59.2 & 11.2 & 2.0 & 27.6 \\
\hline
\end{tabular}




\section{Toilet Facilities}

Access to modern toilet facilities will separate human waste from human contact and consequently reduces households' vulnerability to a range of health risks. Table 5 indicates that $82.8 \%$ of the respondents indicated that they have toilet facilities in their houses. Approximately $17.2 \%$ of the remaining populations claimed that they are less accessible to toilet facilities. More than $50 \%$ of the last category comes principally from the high density area of Lokoja. Some of these respondents interviewed at the high density area claimed that they defecate on erosion channels, uncompleted buildings, open spaces and on the banks of River Niger in the city. This is largely responsible for why Angwan Fulani, Kabawa, Karaworo and Adankolo areas in Lokoja are polluted with stench. To worsen the situation, many of the households interacted with at Agwan Fulani and Kabawa claimed that their wards are more exposed to reptile when defecating along the river channel. They also express their dissatisfaction that there females are prone to different kinds of harassment since they are exposed to passersby. Obviously, these categories of urban dwellers do not live a decent life. Similar observation was made by World Health Organization in 2008 , which reported that $18 \%$ of the world population practices indiscriminate or open defecation.

Table 5: Household Member to toilet

\begin{tabular}{lll}
\multicolumn{2}{c}{ Facilities } & \\
\hline Density Area & Yes & No \\
\hline High Density & 30.1 & 9.7 \\
Medium Density & 35.5 & 4.3 \\
Low Density & 17 & 3.2 \\
Total & 82,8 & 17.2 \\
\hline
\end{tabular}

\section{Types of Toilet Facilities in Lokoja}

Table 6 indicates that $23.1 \%$ of the respondents use pit toilets in the study area. A close observation of many of the pit toilet facilities available to urban dwellers in the city shows that they are dug close to water well, which may contaminate water used for domestic purposes. The remaining $76.9 \%$ of the households sampled claimed that they have water closet in their houses.

Table 6: Toilet Facilities to Households Members in Lokoja

\begin{tabular}{ll}
\hline Toilet Facilities & Percentage \\
\hline Pit toilet & 23.1 \\
Water closet & 76.9 \\
Total & 100.0 \\
\hline
\end{tabular}

\section{Drainage Facility}

Urban centres in Nigeria are less accessible to good drainage facility. Those that have are poorly maintained. The situation in Lokoja is not different from what exists in some other cities in Nigeria. Table 7 shows that $24.5 \%$ of households sampled in the study area have drainage facilities connecting their houses, while the remaining $75.5 \%$ of the respondents indicated that they do not have drainage facilities in their houses. It is disheartening to observe that many of the drainage facilities in the study area are blocked by waste generated by urban dwellers. The offensive odor emanating from many of this drainage are harmful to human health. Even though the sanitation agencies have made concerted efforts to collect waste so as to keep the environment clean but their efforts have proved abortive as the heap of waste along the drainage and road intersections pile up daily in the city. This implies that many of the urban residence may be vulnerable to environmental and health challenges in the city.

Table 7: Drainage Facilities in Lokoja

\begin{tabular}{ll}
\hline Drainage Facility & Percentage \\
\hline No & 24.5 \\
Yes & 75.5 \\
Total & 100.0 \\
\hline
\end{tabular}




\section{Factor Analysis}

Factor analysis has been employed to determine the principal explanatory variable that influences the pattern of housing quality in three residential areas in Lokoja metropolis. The result of factor analysis in Table 8 indicates that five factors whose Eigen value is greater than unity constitutes approximately $82.44 \%$ of the variance of the factors influencing housing quality in the city. Variables loaded on Factor 1 are structural design of the buildings (Age of Buildings $=.606$; Toilet Facilities $=0.799$ and Fence $=0.82$ ) and these accounts for $28.56 \%$ of the variance of the factors influencing housing quality in the city. The result of this analysis is tangential to studies of housing quality in North America, Europe, Egypt and Asia Minor, which emphasis on structural design as well as facilities provided in a house as a perquisite's for decent accommodation(Evans, 2006; Arik and Arik, 2009). Factor 2 accounts for about
$18.62 \%$ of the variance of the factors affecting housing quality in Lokoja. Variable loaded on Factor 2 is (Building Set Back $=0.798)$. Also, Factor 3 which has $14.97 \%$ of the total variance has its variable loaded on socio economic characteristics of the inhabitants of the city (Household size $=$. 626; Household Occupation $=.473$ ). It is obvious that the socio economic characteristics of the inhabitants of the city determine to a larger extent the type of house they occupy. Factor 4 accounts for $13.76 \%$ of the variance of the factors influencing housing quality in the study area. Sanitary facilities provided in the household (Drainage Facility $=$. 771) is the major component matrix loaded on factor 4 . Table 8 indicates that variable loaded on Factor 5 which influences housing quality is the method of waste disposal in the neighborhoods in the city and this accounts for $7.42 \%$ of the variance.

Table 8: Result of Factor Analysis of variables affecting housing Quality in Lokoja Component Matrix

\begin{tabular}{|l|l|l|l|l|l|}
\hline & \multicolumn{5}{|c|}{ Component } \\
\cline { 2 - 6 } & \multicolumn{1}{|l|}{} & 2 & 3 & 4 & 5 \\
\hline Household Size & .584 & .002 & .626 & -417 & .078 \\
\hline Educational background of respondents & -368 & .516 & -584 & -359 & -070 \\
\hline Types of residential Unit occupied & .653 & -102 & .178 & -605 & -141 \\
\hline $\begin{array}{l}\text { What is the average distance of your building from the } \\
\text { next house? }\end{array}$ & -209 & .798 & .271 & .158 & .323 \\
\hline Age of building & .606 & .350 & -127 & .470 & -090 \\
\hline $\begin{array}{l}\text { If you have drainage channel in your house how often do } \\
\text { you clear it in a week? }\end{array}$ & .569 & .468 & -148 & .406 & .251 \\
\hline Do you have toilet facility? & .799 & -142 & .048 & -176 & .185 \\
\hline Do you have drainage channels in your house? & .053 & -227 & .350 & .771 & -318 \\
\hline Is the residential building you are occupying fenced? & .820 & .397 & -251 & .049 & -203 \\
\hline $\begin{array}{l}\text { If there are no toilet facilities in your house where do you } \\
\text { defecate? }\end{array}$ & -319 & .262 & .649 & .184 & -527 \\
\hline $\begin{array}{l}\text { How do you dispose the solid waste from your } \\
\text { neighborhoods? }\end{array}$ & -167 &.-869 & -144 & .017 & .346 \\
\hline Residential Zone & -432 & -526 & .321 & -264 & .374 \\
\hline Occupation & -546 & -013 & .473 & .309 & .187 \\
\hline The name of your house location & .657 & -149 & .379 & .127 & .287 \\
\hline
\end{tabular}

Extraction Method: Principal Component Analysis

5 components extracted 
Table 9: Principal Component Matrix

Total Variance Explained

\begin{tabular}{|l|l|l|l|l|l|l|}
\hline \multirow{2}{*}{ Component } & \multicolumn{4}{|c|}{ Initial Eigenvalues } & \multicolumn{3}{c|}{ Extraction Sums of Squared Loadings } \\
\cline { 2 - 7 } & Total & $\begin{array}{l}\text { \% } \\
\text { Variance }\end{array}$ & $\begin{array}{l}\text { Cumulative } \\
\%\end{array}$ & Total & $\begin{array}{l}\text { \% } \\
\text { Variance }\end{array}$ & $\begin{array}{l}\text { Cumulative } \\
\%\end{array}$ \\
\hline 1 & 3,998 & 28,556 & 28,556 & 3,998 & 28.556 & 28.556 \\
2 & 2,606 & 18,617 & 47,174 & 2,606 & 18.617 & 47.174 \\
3 & 1,976 & 14,112 & 61,286 & 1,976 & 14.976 & 61.286 \\
4 & 1,923 & 13,733 & 75,019 & 1,923 & 13.733 & 75.019 \\
5 & 1,039 & 7,420 & 82,440 & 1,039 & 7.420 & 82.440 \\
6 & .818 & 5,844 & 88,284 & & & \\
7 & .517 & 3,693 & 91,977 & & & \\
8 & .443 & 3,167 & 95,144 & & & \\
9 & .353 & 2.518 & 97.663 & & & \\
10 & .176 & 1.260 & 98.923 & & & \\
11 & .124 & .883 & 99.805 & & & \\
12 & .022 & .158 & 99.963 & & & \\
13 & .005 & .037 & 100.000 & & & \\
14 & $1.000 \mathrm{E}-013$ & $1.002 \mathrm{E}-013$ & 100.000 & & & \\
\hline
\end{tabular}

Extraction Method: Principal Component Matrix

\section{Conclusions and Planning Implications}

This paper has examined the characteristics of housing quality and its health implications in Lokoja, a medium sized city in the north central part of Nigeria. The findings reveal that more than sixty percent of the inhabitants of city live in undignified houses. A large proportion of the households sampled in the study area indicated that they are less accessible to portable water. Further analysis revealed that more than $23 \%$ of the household interviewed indicated that they use pit toilets in their houses. Another $17.2 \%$ of the respondents claimed that they defecate in uncompleted buildings and river channels in the city. The study recommends that sanitary facilities and portable water should be provided to the residents who live in the high density area in Lokoja particularly at Agwan Fulani, Kabawa, Karaworo and Adankolo. There is need to provide low cost housing scheme for people who live in Lokoja. The paper concludes that better housing quality is a responsibility of all and sundry. Thus, the local, state and Federal government should salvage this situation as this would enable the masses to live in a decent accommodation and make residents less vulnerable to contagious diseases in their neighborhood.

\section{References}

Adeoye, N.O. (2012). Spatio-Temporal Analysis of Land Use/Cover Change of Lokoja: A Confluence Town. Journal of Geography and Geology, 4(4): 4051.

Aluko, O. (2011). The Effect of Location and Neighborhood Attributes on Housing Values in Metropolitan Lagos. Ethiopian Journal of Environmental Studies and Management, 4(2): 1-14.

Aribigbola, A. (2008). Housing Policy Formulation in Developing Countries: Evidence from Programme Implementation from Akure, Ondo State, Nigeria. Journal of Human Ecology, 23: 125-134. 
Arik, H. and Arik, M. (2009). Is it Economic Growth or Socioeconomic Development: A Cross-Sectional Analysis of the Determinants of Infant Mortality. The Journal of Developing Areas, 43: 1-55.

Bradley, R.H. and Putnick, D.L. (2012). Housing Quality and Access to Material and Learning Resources within the Home Environment in Developing Countries. Society for Research in Child Development, 83(1): 76-91. Also Available online at:http://onlinelibrary.wiley.com/doi/ 10.1111/j.14678624.2011.01674.x/abstract

Dankani, I.M. (2013). Affordable Housing Provision in Kano North Western Nigeria: The Imperative for the Creation of Sustainable City. International Journal of Management and Social Sciences Research, 2(8): 189-198.

Evans, G.W. (2006). Child Development and the Physical Environment. Annual Review of Psychology, 57:423-451. [PubMed </pubmed/16318602>]

Fiadzo, E. (2004). Joint Centre for Housing Studies, Harvard University Estimating the determinants of housing quality: The case of Ghana. Paper No. W04-6

Gambo, Y.L., Idowu, O.B. and Anyakora, I.M. (2012). Impact of Poor Housing Condition on the Economy of the Urban Poor, Maroko, Lagos State in View. Journal of Emerging Trends in Economics and Management Science (JETEMS), 3(4): 302-307.

Lindskog, P. and Lundqvist, J. (1998). Why Poor Children Stay Sick: The Human Ecology of Child Health and Welfare in Rural Malawi. Uppsala:
Scandinavian Institute of African Studies.

Meng, G. and Hall, G.B. (2006). Assessing Housing Quality in Metropolitan Lima, Peru. Journal of Housing and the Built Environment, 21: 413-439.

Muoghalu, L. (1991). Measuring Housing and Environmental Quality as an Indicator of Quality of Urban life: A case of Traditional City of Benin, Nigeria. Social Indicators Research, 25: 63-98.

Olawepo, R.A. (2009). Evaluating Housing Problems through Participatory Rural Appraisal in Lokoja, Nigeria. African Research Review, 3(1): 77-96.

Roberts, L., Chartier, Y., Chartier, O., Malenga, G., Toole, M. and Rodka, H. (2001). Keeping Clean Water Clean in aMa lawi Refugee Camp: A Randomized Clinical Trial. Bulletin of the World Health Organization, 79:280-287. [PMC free article mc/articles/PMC2566389/>][PubMed $<$ /pubmed/11357205>]

Unicef and World Health Organization in (2008): 6 in 10 Africans Remain Without Access to Proper Toilet: Poor Sanitation Threatens Public Health. Also Available online at: http://onlinelibrary.wiley.com/doi/10 $.1111 / \mathrm{j} .1467-$ 8624.2011.01674.x/abstract

World Health Organiztion (2008). Global Burden of Disease, 2004 update. 2008 Available online: http://www.who.int/healthinfo/global_ burden_disease/en/index.html.http://w ww.who.int/water_sanitation_health/d wq/en/ http://www.who.int/mediacentre/news/ releases/2008/pr 